\title{
Thermostability of Photosynthesis of Vitis aestivalis and $V$. vinifera
}

\author{
Sorkel Kadir ${ }^{1}$ \\ Department of Horticulture, Forestry, and Recreation Resources, Kansas State University, Manhattan, \\ KS 66506
}

\begin{abstract}
AdDitional index words. 'Semillon', 'Pinot Noir', 'Chardonnay', 'Cabernet Sauvignon', 'Cynthiana', chlorophyll fluorescence, thylakoid membranes, chlorophyll content

Aвstract. High temperature adversely affects photosynthetic rates and thylakoid activities in many species, but photosynthesis response to heat stress is not well defined in grapes (Vitis L.). Genotypes within species respond differently to high temperatures, indicating a genetic variability for the trait. The objective of this study was to determine the physiological responses of two grape species to high temperature, at the whole-plant level and at the cellular level. Gas exchange, relative chlorophyll content, and chlorophyll fluorescence of intact leaves and thermostability of extracted thylakoids of the American (V. aestivalis Michx.) 'Cynthiana' and European ( $V$. vinifera L.) 'Semillon', 'Pinot Noir', 'Chardonnay', and 'Cabernet Sauvignon' wine grapes were evaluated. One-year-old vines were placed in controlled environmental chamber held at $20 / 15,30 / 25$, or $40 / 35{ }^{\circ} \mathrm{C}$ day/night for 4 weeks. $\mathrm{Net}_{\mathrm{CO}}$ assimilation (A) rate, stomatal conductance $\left(\mathrm{g}_{\mathrm{s}}\right)$, transpiration $(\mathrm{E})$ rate, chlorophyll content, and chlorophyll fluorescence of intact leaves were measured at weekly intervals. Chlorophyll fluorescence of thylakoids extracted from $V$. aestivalis 'Cynthiana' and $V$. vinifera 'Pinot Noir' subjected to temperatures ranging from 20 to $50{ }^{\circ} \mathrm{C}$ was measured. Optimal temperatures for photosynthesis were $20 / 15{ }^{\circ} \mathrm{C}$ for 'Cynthiana' and 'Semillon' and $30 / 25^{\circ} \mathrm{C}$ for the other three $\mathrm{V}$. vinifera cultivars. The A, $\mathrm{g}_{\mathrm{s}}$, E, chlorophyll content, and chlorophyll fluorescence values at $40 / 35^{\circ} \mathrm{C}$ were lower in 'Cynthiana' than 'Pinot Noir'. In general, reduction of A coincided with decline in $\mathrm{g}_{\mathrm{s}}$ in 'Cynthiana', whereas no strong relationship between $\mathrm{A}$ and $\mathrm{g}_{\mathrm{s}}$ was observed in $V$. vinifera cultivars. Variable chlorophyll fluorescence ( $F v)$ and the quantum efficiency of photosystem II (Fv/Fm) of intact leaves for all the cultivars decreased at $40 / 35^{\circ} \mathrm{C}$, with severe decline in ' $\mathrm{Cynthiana}$ ' and 'Cabernet Sauvignon,' moderate decline in 'Semillon' and 'Chardonnay', and slight decline in 'Pinot Noir'. A distinct effect of high temperature on Fv and Fv/Fm of 'Cynthiana' was exerted after 2 weeks of exposure. Prolonged-exposure to 40/35 ${ }^{\circ} \mathrm{C}$ led to $78 \%$ decrease in Fv/Fm in 'Cynthiana', compared with $8 \%$ decrease in 'Pinot Noir'. In general, Fv and Fv/Fm of extracted thylakoids declined as temperature increased, with more decline in 'Cynthiana' than in 'Pinot Noir'. Based on A rates and $\mathrm{Fv} / \mathrm{Fm}$ ratios, results showed that ' $\mathrm{Cynthiana'}$ has lower optimal temperature for photosynthesis $(20 / 15$ $\left.{ }^{\circ} \mathrm{C}\right)$ than 'Pinot Noir' $\left(30 / 25^{\circ} \mathrm{C}\right)$. Chlorophyll fluorescence responses of intact leaves and extracted thylakoids to high temperatures indicate that 'Pinot Noir' possess higher photosynthetic activity than 'Cynthiana'. Results of this work could be used in selection programs for the development of heat resistant cultivars in the warmest regions.
\end{abstract}

Productivity of temperate species falls significantly at high temperatures. Photosynthesis is the most sensitive process at high temperatures, especially during vegetative stages (Salvucci and Crafts-Brandner, 2004) and reproductive growth (Moffatt et al., 1990). Photosystem II (PSII) has been reported to be more sensitive than photosystem I(PSI) to heat stress (Berry and Björkman, 1980). The PSII reaction center is especially damaged mostly near the water-oxidizing complex (Wise et al., 2004). Wheat (Triticum aestivium L.) PSII has greater sensitivity to heat stress than rice (Oryza sativa L.) and millet [Pennesitum glaucum (L.) R. Br.] PSII (Al-Khatib and Paulsen, 1999); thus differences within genotypes indicate significant genetic variability for the trait. The adverse effect of high temperature on thylakoid activities has been reported to be more severe than that on the chloroplast envelope or stromal enzyme components (Santarius, 1975).

Inhibition of photosynthesis by high temperature is due to alteration in thylakoid membranes integrity (Gounaris et al.,

Received for publication 7 Feb. 2006. Accepted for publication 29 Apr. 2006. With my appreciation, funding for this study was provided by Kansas Agricultural Experiment Station. This is contribution no. 06-79-J from the Kansas Agricultural Experiment Station, Manhattan, Kansas. We thank Gary Paulsen for the use of the chlorophyll fluorometer and growth chambers and Kassim Al-Khatib for the use of photosynthesis measurement system. Mention of a trademark does not imply endorsement of the product.

${ }^{1}$ Assistant Professor and corresponding author; E-mail address: skadir@ksu. edu.
1983; Schrader et al., 2004) and reduction of the activation state of ribulose-1,5-bisphosphate carboxylase/oxygenase (Rubisco) (Kobza and Edward, 1987). Dissociation of the major light-harvesting complex of PSII from the core complex can be attributed to the increased fluidity of the thylakoid membrane (Armond et al., 1980). Damaged thylakoid membranes by high temperature show an increase in the amount of initial chlorophyll fluorescence emission (Kim and Portis, 2005), which indicates damage to the electron transport system of photosynthesis. The ability to resist heat stress differs among plants grown at contrasting thermal environments due to the ability of a plant to accumulate heatshock proteins and increase thermostability of the membranes (Haldimann and Feller, 2005) by altering thylakoid lipid composition (Li et al., 2003; Sharkey, 2005; Tardy and Havaux, 1997). Progressive acclimation to increased temperature significantly improved thermostablity of the thylakoid membranes and photosynthetic electron transport of pea (Pisum sativum L.) plants (Haldimann and Feller, 2005).

Heat stress can reduce net $\mathrm{CO}_{2}$ assimilation (A) rate, stomatal conductance $\left(\mathrm{g}_{\mathrm{s}}\right)$ and transpiration (E) rates, and increase leaf temperature (Dubey, 1997; Falk et al., 1996). Nevertheless, $g_{s}$ in blackberry (Rubus L. subgenus Rubus Watson) was not the limiting factor to $\mathrm{A}$ at temperatures up to $35^{\circ} \mathrm{C}$ (Stafne et al., 2001). Reduction in photosynthesis has been reported to be related to biochemical factors (Ferrini et al., 1995; Medrano et al., 2003) rather than to $\mathrm{g}_{\mathrm{s}}$ (Hancock et al., 1992). 
Damage to the photosynthetic apparatus results in reduction in $\mathrm{CO}_{2}$-fixation, ultimately, reduction in the rate of growth. Most of the photosynthate of grape is used for respiration, which is required for growth and organ maintenance (Blanke, 1990). High temperature affects the partitioning and translocation of photosynthates to plant parts other than the clusters (Sepulveda et al., 1986), thus affecting fruit set and berry compositions. Fruit set is inhibited by temperatures above $35^{\circ} \mathrm{C}$ due to reduction in ovule or pollen viability and pollen tube growth, which contribute to smaller berry size and yield reduction (Ewart and Kliewer, 1977; Song and Ko, 1999). Extended periods of high temperature delays fruit maturation, reduces total titratable acidity (Kliewer, 1971), increases pH (Kliewer, 1968), and reduces berry color development (Kliewer, 1970).

Grapes are generally grown in the warmest regions in the world, where maximum air temperature can reach more than $40{ }^{\circ} \mathrm{C}$ (Williams et al., 1994), but the optimum temperature for photosynthesis has been established for some grapevines to be between 25 and $35^{\circ} \mathrm{C}$ (Mullins et al., 1992). The wide variation in temperature range is due to species, cultivars, environmental conditions, or seasonal temperature variation (Ferrini et al., 1995; Shiraishi et al., 1996; Song and Ko, 1999). Temperatures above $35^{\circ} \mathrm{C}$ generally reduce photosynthesis for both the American and V. vinifera species (Gamon and Pearcy, 1990), but the V. vinifera cultivars can survive temperatures up to $40{ }^{\circ} \mathrm{C}$ for a short period of time (Mullins et al., 1992).

For the last 15 years, grape has become one of the most productive and important specialty crops throughout the midwestern United States. The American and French-American hybrid wine grapes are widely grown in the midwestern United States due to their cold hardiness. 'Cynthiana' is one of the most widely planted $V$. aestivalis red wine cultivars, due to its cold hardiness and production of rich, dark-red wines with spicy, raspberryscented aromas.

Little information exists on the mechanism by which $V . v i$ nifera cultivars survive high temperatures compared to the $V$. aestivalis 'Cynthiana' wine grape; therefore, the work presented in this paper was to assess thermostability of photosynthesis of Vitis germplasms over moderate to high temperatures. The objectives of this study were to determine optimum temperatures for photosynthesis, measure responses of grape vines to high temperature, and rank the relative heat tolerance of cultivars. On a cellular level and based on results of chlorophyll fluorescence of intact leaf that showed 'Cynthiana' was the most sensitive to high temperature while 'Pinot Noir' was the least sensitive, thylakoid membrane activity of both was compared under high temperatures to establish thermostability of the two cultivars. Results of this work could be used in selection programs for the development of winegrape cultivars resistant to high temperature for the warmest zones.

\section{Material and Methods}

Plant materials and treatments. Self-rooted $V$. aestivalis red winegrape 'Cynthiana' was compared with four $V$. vinifera winegrape cultivars grafted onto 3309 rootstocks: 'Semillon' clone 5 (white); 'Pinot Noir' clone 667 (red); 'Chardonnay' clone 4 (white); and 'Cabernet Sauvignon' clone 169 (red). Dormant 1-year-old vines (Double A Vineyards, Fredonia, N.Y.) were planted in polyethylene pots $(16.25 \times 16.25 \times 12.5 \mathrm{~cm})$ containing a mixture of 1 sand : 1 peatmoss : 1 perlite (by volume). Each pot had six drainage holes at the bottom to facilitate water drainage.
Vines were placed in the greenhouse at $22 / 17 \pm 3{ }^{\circ} \mathrm{C}$ day/night $(\mathrm{D} / \mathrm{N})$ temperatures, $50 \% \pm 10 \%$ relative humidity $(\mathrm{RH})$, and $16 / 8$ $\mathrm{h}$ photoperiods. Supplemental light intensity on a horizontal plane above the canopy was $200 \mu \mathrm{mol} \cdot \mathrm{m}^{-2} \cdot \mathrm{s}^{-1}$ photosynthetic photon flux density (PPFD) [400-700 nm, measured with LI-188B Integrating Quantum/Radiometer/Photometer and LI-190sB sensor (LI-COR, Lincoln, Nebr.)] using Hydrofarm grow lights with 400W, high-pressure sodium S-51 type-lamps (Hydrofarm Products, Petaluma, Calif.). Vines were irrigated to full pot capacity (Olson et al., 2000) and fertilized weekly with a commercial fertilizer containing $300 \mu \mathrm{g} \cdot \mathrm{L}^{-1}$ nitrogen, $250 \mu \mathrm{g} \cdot \mathrm{L}^{-1}$ phosphorus, and 220 $\mu \mathrm{g} \cdot \mathrm{L}^{-1}$ potassium (Miracle-Gro; Scotts Miracle-Gro Products, Port Washington, N.Y.).

After 5 weeks, vines were pruned to a single shoot per vine, and gas exchange, relative chlorophyll content, and chlorophyll fluorescence of the most recent fully expanded leaf were measured. Measurements before applying temperature treatments were considered as the control. Vines per cultivar were divided into three groups, each of four vines, placed in one of the three growth chambers (CMP 3244; Conviron, Asheville, N.C.) for 4 weeks. Growth chambers were set at $20 / 15 \pm 1^{\circ} \mathrm{C}, 30 / 25 \pm 1{ }^{\circ} \mathrm{C}$, and $40 / 35 \pm{ }^{\circ} \mathrm{C} 1 \mathrm{D} / \mathrm{N}$ temperatures, $16 / 8 \mathrm{~h}$ photoperiods, and $550 \mu \mathrm{mol} \cdot \mathrm{m}^{-2} \cdot \mathrm{s}^{-1} \mathrm{PPFD}$. Humidity was not regulated, but was monitored to be in the range from $40 \% \pm 10 \%$ during the light period to $70 \% \pm 10 \% \mathrm{RH}$ during the dark period. Vines at 20/15, $30 / 25$, and $40 / 35^{\circ} \mathrm{C}$ were watered as needed to full pot capacity. Besides daily watering, plants at $40 / 35^{\circ} \mathrm{C}$ were misted every 30 min to prevent secondary injury due to desiccation. Gas exchange, relative chlorophyll content, and chlorophyll fluorescence of intact leaves were measured at weekly intervals, for 4 weeks at the temperature treatments, between 0900 and 1100 HR. Leaves from 5-week-old self-rooted 'Cynthiana' and 'Pinot Noir' clone 667 grafted onto 3309 rootstock grown in the greenhouse under similar conditions described earlier, were collected and thermostability of extracted thylakoids was measured.

Gas eXChange and Relative Chlorophyll Content. Gas exchange was measured by using LI-6400 open system portable photosynthesis measurement (LI-COR). Leaf net $\mathrm{CO}_{2}$ assimilation $(\mathrm{A})$ rate and stomatal conductance $\left(\mathrm{g}_{\mathrm{s}}\right)$ were determined for 4 weeks. Due to equipment failure, transpiration (E) rates were determined for weeks three and four only. An intact leaf was placed in the leaf chamber $\left(6.0 \mathrm{~cm}^{2}\right)$ and exposed to 2000 $\mu \mathrm{mol} \cdot \mathrm{m}^{-2} \cdot \mathrm{s}^{-1}$ PPFD and $\mathrm{CO}_{2}$ concentration of $400 \mu \mathrm{L} \cdot \mathrm{L}^{-1}$. Data were recorded after $\approx 30$ to $45 \mathrm{~s}$, when $\mathrm{CO}_{2}$ and stomatal conductance stabilized.

Leaf chlorophyll meter (SPAD-501; Minolta Corp., Osaka, Japan) was used to measure indirect index of chlorophyll content under temperature treatments. Three SPAD measurements (38 $\mathrm{mm}^{2}$ total leaf area) were taken from locations between the veins. Data were averaged for each leaf of the replicated grapevines to represent one observation.

INTACT LEAF CHLOROPHYLL FLUORESCENCE. Leaf chlorophyll fluorescence emission was determined using a pulse-modulated fluorescence monitoring system (FMS-1; Hansatech Instruments Ltd., Norfolk, England) operated in the Fv/Fm mode. The fluorometer probe was placed $7 \mathrm{~mm}$ away from the leaf surface and measurements were made at steady state of $2000 \mu \mathrm{mol} \cdot \mathrm{m}^{-2} \cdot \mathrm{s}^{-1}$ and saturating state of $5000 \mu \mathrm{mol} \cdot \mathrm{m}^{-2 \cdot} \cdot \mathrm{s}^{-1}$ for $0.7 \mathrm{~s}$ when all of the PSII reaction centers were reduced. Initial fluorescence $(\mathrm{Fo})$ when plastoquinone electron acceptor pool (Qa) is fully oxidized, maximal fluorescence (Fm) when Qa is transiently fully reduced, variable fluorescence $(\mathrm{Fv}=\mathrm{Fm}-\mathrm{Fo})$, and maximum quantum 
efficiency of PSII (Fv/Fm) were recorded. Three readings from the center of the leaf of each vine were averaged to represent one observation.

Thylakoid EXtraction and TREatments. Chloroplast thylakoids were extracted as described previously (Al-Khatib and Paulsen, 1990). Leaves were homogenized with a Polytron (Brinkmann Instruments, Westbury, N.Y.) for 1 min in ice-cold medium of $330 \mathrm{~mm}$ sorbitol, $40 \mathrm{~mm} N$-2-hydroxyethylpiperazine$N$-2-ethanesulfonic acid (Hepes-NaOH) ( $\mathrm{pH} 7.0), 30 \mathrm{~mm} \mathrm{KCl}$, and $3 \mathrm{mM} \mathrm{MgCl}_{2}$, then all subsequent operations were carried out at $0{ }^{\circ} \mathrm{C}$. The homogenate was centrifuged at $750 g_{\mathrm{n}}$ for $1 \mathrm{~min}$, and the supernatant was centrifuged at $2500 g_{\mathrm{n}}$ for another $2 \mathrm{~min}$. The pellet from the second centrifugation was suspended in 10 $\mathrm{mm} \mathrm{NaCl}$, centrifuged at $2500 g_{\mathrm{n}}$ for $10 \mathrm{~min}$, and washed twice before being taken up in the original extraction medium. Chlorophyll concentration was $30 \mathrm{mg} \cdot \mathrm{mL}^{-1}$, preparation for temperature treatments were made within $30 \mathrm{~min}$. Temperature treatments were imposed on $0.2 \mathrm{~mL}$ chloroplast thylakoid samples in thin glass tubes placed in several controlled-temperature baths (Haake Buchler Instruments, Saddle Brook, N.J.) set at 20, 30, 40, 45, or $50{ }^{\circ} \mathrm{C}$ for $2 \mathrm{~min}$, with gentle agitation. After $2 \mathrm{~min}$, samples were taken out of each bath and kept in ice prior to measurement. The above procedure was carried out under room temperature (22-23 ${ }^{\circ} \mathrm{C}$ ) and lighting of $15 \mu \mathrm{mol} \cdot \mathrm{m}^{-2} \cdot \mathrm{s}^{-1} P P F D$.

Thylakoid Fluorescence Measurement. Chlorophyll fluorescence was conducted according to the method of Al-Khatib and Paulsen (1990). Fluorescence was measured by adding 0.2 $\mathrm{mL}$ of thylakoid-extract, containing $2 \mathrm{mg} \cdot \mathrm{L}^{-1}$ chlorophyll and $3 \mathrm{~mL}$ of PSII media to the Hansatech DW1 oxygen electrode unit (King's Lynn, England). The PSII media consisted of 50 mM HEPES-NaOH (pH 7.6), 15 mm 3-(3,4-dichlorophenyl)1,1-dimethylurea, $10 \mathrm{~mm} \mathrm{KCl}$, and $5 \mathrm{~mm} \mathrm{MgCl}_{2}$. The plant efficiency analyzer [PEA (Hansatech Instruments Ltd., Norfolk, England)] sensor head was placed over the unit, and thylakoids were dark-adapted by covering the unit with a black fabric for 2 min before measurement. The oxygen electrode unit was fitted with two Hansatech FDP photodiode detectors protected by 685 - and 740-nm center bandpass interference filters with bandwidths of 12-nm (Ealing Electro-Optics, South Natick, Mass.) to detect fluorescence. Excitation radiation from a quartz halogen lamp (Oriel Corp., Stamford, Conn.) equipped with Ilex shutter (Melles Griot, Rochester, N.Y.), Schott BG-39 shortpass filter (586-nm cutoff), and neutral density filters (Schott Glass Technologies, Duryea, Pa.) provided $100 \mu \mathrm{mol} \cdot \mathrm{m}^{-2} \cdot \mathrm{s}^{-1}$ irradiance. Temperature of the unit was maintained at $22^{\circ} \mathrm{C}$ by a Haake A80 refrigerated circulating bath (Haake-Buchler, Saddle Brook, N.J.). Fluorescence photodiode signals were processed by an EXP-16 multiplexer and DAS-16 converter (MetraByte Corp., Taunton, Mass.) interface-computer system.

EXPERIMENTAL DESIGNS AND DATA ANALYSIS. The experiments were randomized complete-block designs with factorial arrangement of cultivar $\times$ temperature $\times$ time for the intact leaf study and cultivar $\times$ temperature for the thylakoid heat treatment study. Treatments were replicated four times for the intact leaf study and six times for the thylakoid heat treatment study. The replications in the thylakoid heat study were independent extractions. Experiments were repeated; data are averaged across both runs since there was no interaction between treatments and runs. Temperature treatment response was determined by conventional analyses of variance (ANOVA) or general linear model (GLM) as appropriate. Least significant differences (LSD) among means were tested at $P=0.05$, and precision was measured by coef- ficient of variation (Cv) percentage. Standard errors of treatment means were calculated. Data are presented as percentages of measurements taken before temperature treatments. Acorrelation coefficient between photosynthetic parameters was established. Data were tested for homogeneity of variance and normality of distribution (Ramsey and Schafer, 1997). Three-way interactions of cultivar $\times$ temperature $\times$ time were found for all intact leaf parameters, except a two-way interaction for cultivar $\times$ temperature was statistically significant for the transpiration rate. There was significant two-way interaction for chlorophyll fluorescence parameters for the thylakoid heat treatment study.

\section{Results}

Gas eXchange. All cultivars subjected to 1 week of 20/15 ${ }^{\circ} \mathrm{C}$ had more than $95 \%$ of the net $\mathrm{CO}_{2}$ assimilation (A) rates of the control (Fig. 1). After 4 weeks of exposure to $20 / 15^{\circ} \mathrm{C}$,
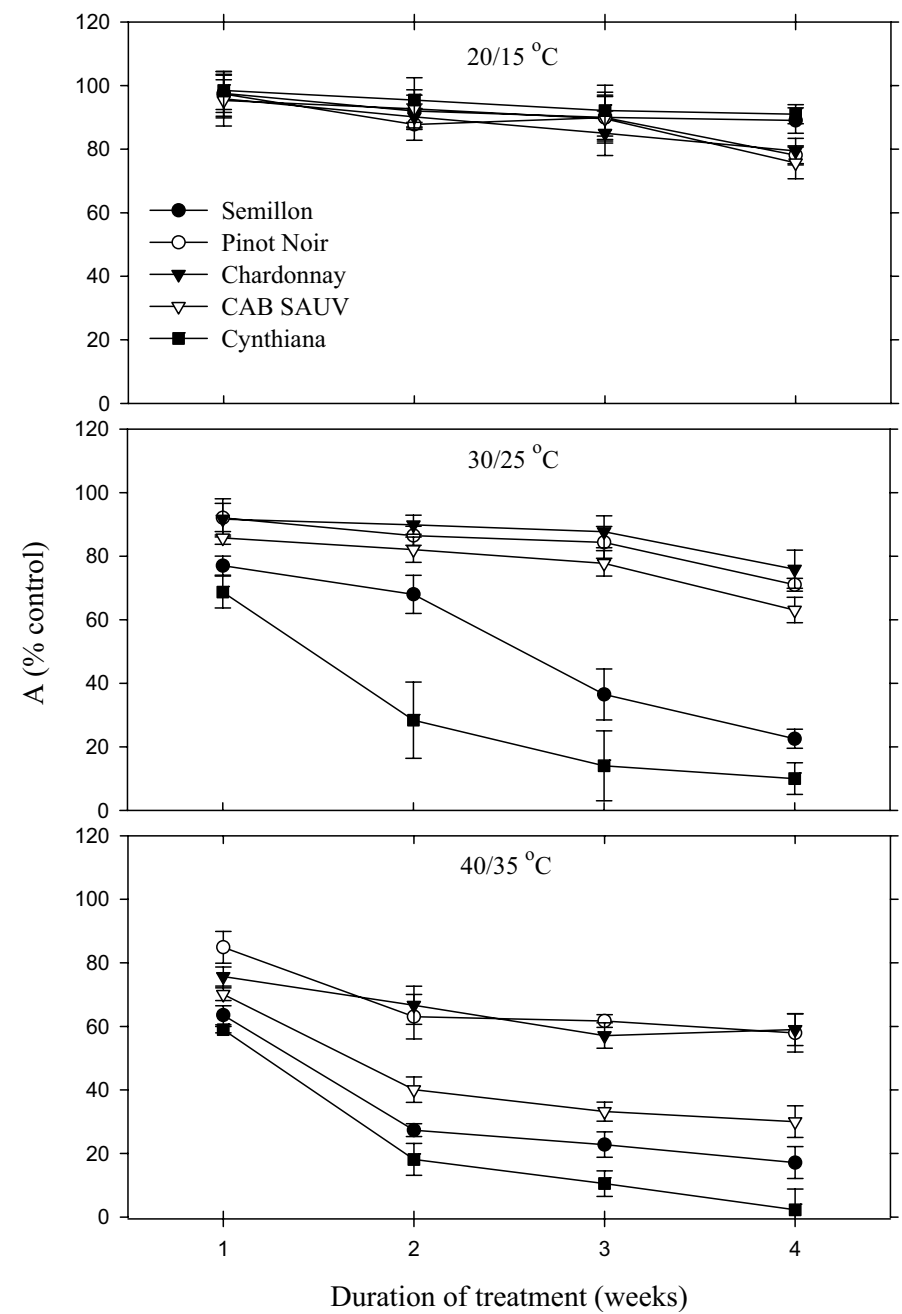

Fig. 1. Net $\mathrm{CO}_{2}$ assimilation rate (A) of attached leaves of Vitis vinifera 'Semillon', 'Pinot Noir', 'Chardonnay', 'Cabernet Sauvignon' (CAB SAUV), and V.aestivalis 'Cynthiana' after temperature treatments. Attached leaves were on 35 -d-old plants grown at $20 / 15,30 / 25$, or $40 / 35^{\circ} \mathrm{C}$ day/night $(\mathrm{D} / \mathrm{N})$ and $16 / 8 \mathrm{~h}$ photoperiod for 4 weeks. Photosynthetic rates were measured at $\mathrm{CO}_{2}$ concentration of $400 \mu \mathrm{L} \cdot \mathrm{L}^{-1}$, at weekly intervals. Vertical lines through data points represent the SE; values smaller than symbols are not shown. Control values $\left(\mu \mathrm{mol} \cdot \mathrm{m}^{-2} \cdot \mathrm{s}^{-1}\right)$ were: 'Semillon' (16.1), 'Pinot Noir' (15.1), 'Chardonnay' (15.9), 'Cabernet Sauvignon' (15), and 'Cynthiana' (12.9). The control treatment was measured at $22 / 17 \pm 3{ }^{\circ} \mathrm{C} \mathrm{D} / \mathrm{N}$ and $16 / 8 \mathrm{~h}$ photoperiod. 
temperature had no significant effect on A rates in 'Cynthiana' or 'Semillon', compared to week one, whereas Adecreased in 'Pinot Noir', 'Chardonnay', and 'CabernetSauvignon'. 'Cynthiana' and 'Semillon' had the highest A rates (91\% and 89\%, respectively), compared with an average of $78 \%$ for the other cultivars.

After 1 week at $30 / 25{ }^{\circ} \mathrm{C}$, A was reduced for 'Semillon' and 'Cynthiana', whereas A rates were not altered in the other cultivars at this duration of treatment. Photosynthetic activity in 'Cynthiana' and 'Semillon' declined as time of exposure to 30/25 ${ }^{\circ} \mathrm{C}$ increased to 4 weeks. At a given time, reduction in A rate was more pronounced in 'Cynthiana' than in 'Semillon'. 'Chardonnay' (75\%) and 'Pinot Noir' $(72 \%)$ had the highest A rates after 4 weeks of exposure to $30 / 25^{\circ} \mathrm{C}$. Leaf photosynthesis of all the cultivars decreased at $40 / 35^{\circ} \mathrm{C}$. In general and throughout the experiment, 'Cynthiana' had the lowest A rates, whereas 'Pinot Noir' and 'Chardonnay' had the highest rates. Photosynthesis of 'Cynthiana' at $40 / 35{ }^{\circ} \mathrm{C}$ was reduced to $19 \%$ after 2 weeks of exposure, compared with $63 \%$ and $66 \%$ in 'Pinot Noir' and 'Chardonnay', respectively. 'Cynthiana' leaves were nearly killed showing dry leaf surface with very few green spots after 4 weeks of exposure to high temperature, whereas A rate was reduced to $58 \%$ and $59 \%$ for 'Pinot Noir' and 'Chardonnay', respectively.

Stomatal conductance $\left(\mathrm{g}_{\mathrm{s}}\right)$ differed distinctly among the cultivars (Fig. 2). Throughout the experiment, $g_{s}$ at $20 / 15^{\circ} \mathrm{C}$ was the highest in 'Cynthiana', although 'Semillon' had similar rate at week one. After more than 3 weeks of exposure to $20 / 15^{\circ} \mathrm{C}$, 'Pinot Noir' (37\%) and 'Chardonnay' (32\%) had the lowest $g_{s}$, whereas 'Semillon' and 'Cabernet Sauvignon' were intermediate. Stomatal conductance of 'Cynthiana', 'Chardonnay', and 'Cabernet Sauvignon' at $30 / 25^{\circ} \mathrm{C}$ was significantly reduced after 1 week of exposure. At the end of the experiment, $g_{\mathrm{s}}$ values were higher in 'Pinot Noir' (63\%) and 'Semillon' (67\%) than in the other cultivars. Vines of 'Pinot Noir' and 'Cynthiana' grown at $40 / 35^{\circ} \mathrm{C}$ for 4 weeks had the lowest $\mathrm{g}_{\mathrm{s}}$ with $26 \%$ and $16 \%$ of the control, respectively, whereas 'Cabernet Sauvignon' had the highest value (92\%).

Time of exposure had no effect on E rates; nevertheless there was two-way interaction for cultivar $\times$ temperature. Data presented in Table 1 are average of 2 weeks. 'Cynthiana' at $20 / 15^{\circ} \mathrm{C}$ had the highest $\mathrm{E}$ rate of $2.1 \mathrm{~mol} \cdot \mathrm{m}^{-2} \cdot \mathrm{s}^{-1}$, whereas 'Pinot Noir' had the lowest rate of $0.56 \mathrm{~mol} \cdot \mathrm{m}^{-2} \cdot \mathrm{s}^{-1}$. At $30 / 25^{\circ} \mathrm{C}$, 'Semillon' (2.4 $\left.\mathrm{mol} \cdot \mathrm{m}^{-2 \cdot} \cdot \mathrm{s}^{-1}\right)$ and 'Pinot Noir' $\left(1.85 \mathrm{~mol} \cdot \mathrm{m}^{-2} \cdot \mathrm{s}^{-1}\right)$ had the highest

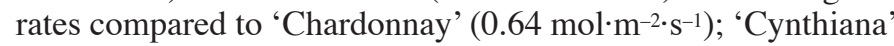
and 'Cabernet Sauvignon' were intermediate. 'Cynthiana' leaves at $40 / 35^{\circ} \mathrm{C}$ transpired the least $\left(0.55 \mathrm{~mol} \cdot \mathrm{m}^{-2} \cdot \mathrm{s}^{-1}\right)$, whereas ' $\mathrm{Cab}$ ernet Sauvignon' leaves transpired the most $\left(3.96 \mathrm{~mol} \cdot \mathrm{m}^{-2} \cdot \mathrm{s}^{-1}\right)$. In general, $V$. vinifera cultivars transpired the most at high temperature, with an average rate of $2.63 \mathrm{~mol} \cdot \mathrm{m}^{-2} \cdot \mathrm{s}^{-1}$, compared with 'Cynthiana'.

Chlorophyll content. After 2 weeks of exposure to 20/15 ${ }^{\circ} \mathrm{C}$, relative chlorophyll content (SPAD units) was not altered in any of the cultivars (Fig. 3). More than 3 weeks of exposure, however, chlorophyll content increased in 'Semillon' to $133 \%$ of the control, but decreased to the same level of week one in 'Cabernet Sauvignon' (109\%). No significant changes were observed in the other cultivars.

After 1 week of exposure to $30 / 25^{\circ} \mathrm{C}$, chlorophyll content of 'Cynthiana' was the highest $(137 \%)$, although a significant decline to $75 \%$ was observed after 4 weeks of exposure. Among the $V$. vinifera cultivars, 'Semillon' had the highest chlorophyll content of $130 \%$ after 4 weeks of exposure to $30 / 25^{\circ} \mathrm{C}$, whereas no change was observed in the other cultivars. There were sig-
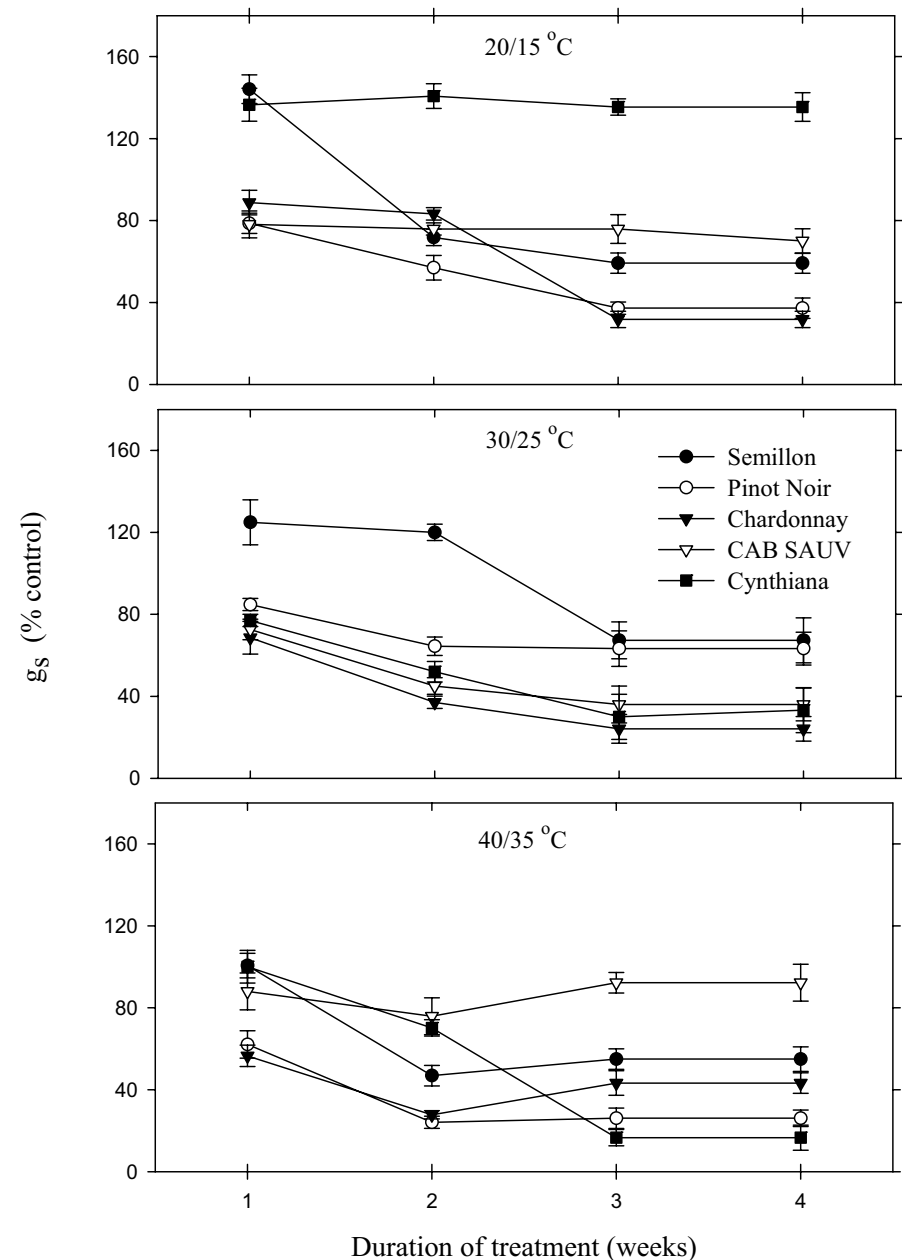

Fig. 2. Stomatal conductance ( $\mathrm{g}_{\mathrm{s}}$ ) of attached leaves of Vitis vinifera 'Semillon', 'Pinot Noir', 'Chardonnay', 'Cabernet Sauvignon' (CAB SAUV), and Vitis aestivalis 'Cynthiana' after temperature treatments. Attached leaves were on 35 -d-old plants grown at $20 / 15,30 / 25$, or $40 / 35^{\circ} \mathrm{C}$ day/night $(\mathrm{D} / \mathrm{N})$ and $16 / 8 \mathrm{~h}$ photoperiod for 4 weeks. Stomatal conductance was measured at $\mathrm{CO}_{2}$ concentration of $400 \mu \mathrm{L} \cdot \mathrm{L}^{-1}$, at weekly intervals. Vertical lines through data points represent the SE; values smaller than symbols are not shown. Control values (mmol $\left.\cdot \mathrm{m}^{-2} \cdot \mathrm{s}^{-1}\right)$ are: 'Semillon'(0.144), 'Pinot Noir'(0.198), 'Chardonnay' (0.206), 'Cabernet Sauvignon' (0.088), and 'Cynthiana' (0.209). The control treatment was measured at $22 / 17 \pm 3{ }^{\circ} \mathrm{C} \mathrm{D} / \mathrm{N}$ and $16 / 8 \mathrm{~h}$ photoperiod.

Table 1. Intact leaf transpiration rate (E) of Vitis vinifera 'Semillon', 'Pinot Noir', 'Chardonnay', 'Cabernet Sauvignon', and V. aestivalis 'Cynthiana' in response to $20 / 15^{\circ} \mathrm{C}, 30 / 25{ }^{\circ} \mathrm{C}$, or $40 / 35{ }^{\circ} \mathrm{C}$ under controlled environmental conditions. ${ }^{\mathrm{z}}$

\begin{tabular}{|c|c|c|c|c|}
\hline Semillon & Pinot Noir & Chardonnay & $\begin{array}{l}\text { Cabernet } \\
\text { Sauvignon }\end{array}$ & Cynthiana \\
\hline \multicolumn{5}{|c|}{-----------Leaf transpiration rate $\left[\mathrm{H}_{2} \mathrm{O}\left(\mathrm{mol} \cdot \mathrm{m}^{-2} \cdot \mathrm{s}^{-1}\right)\right]-----------$} \\
\hline & & $\underline{20 / 15^{\circ} \mathrm{C}}$ & & \\
\hline \multirow[t]{2}{*}{1.15} & 0.56 & 1.02 & 1.58 & 2.1 \\
\hline & & $\underline{30 / 25^{\circ} \mathrm{C}}$ & & \\
\hline \multirow[t]{2}{*}{2.40} & 1.85 & 0.64 & 1.17 & 1.04 \\
\hline & & $\underline{40 / 35^{\circ} \mathrm{C}}$ & & \\
\hline 2.95 & 1.66 & 2.01 & 3.96 & 0.55 \\
\hline $\mathrm{LSD}_{0.05}$ & & 0.6 & & \\
\hline
\end{tabular}

${ }^{\mathrm{z}}$ Average of 2 weeks. Equipment failure prevented recording data from weeks 0,1 , and 2 . 


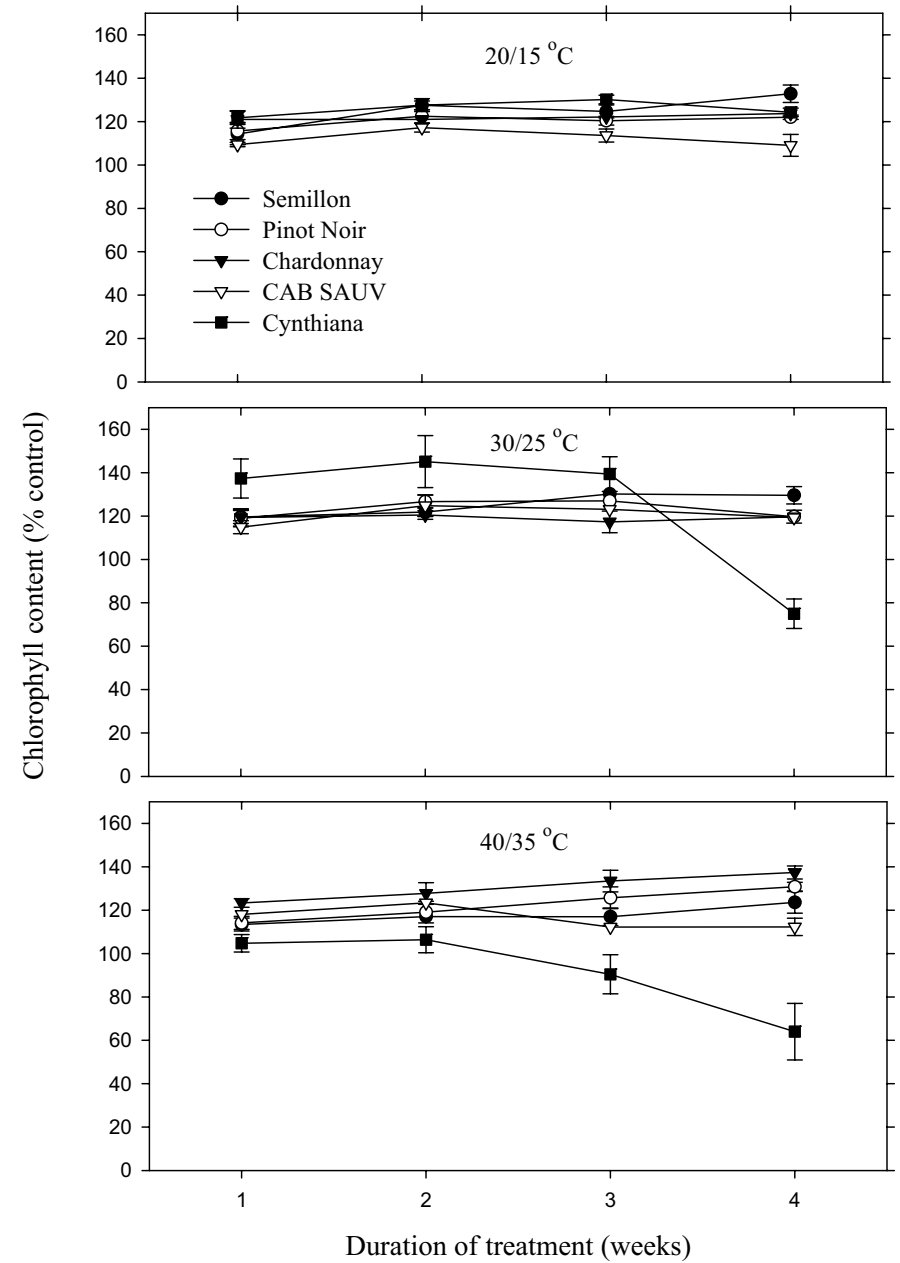

Fig. 3. Relative chlorophyll content of attached leaves of Vitis vinifera 'Semillon', 'Pinot Noir', 'Chardonnay', 'Cabernet Sauvignon' (CAB SAUV), and V. aestivalis 'Cynthiana' after temperature treatments. Attached leaves were on 35 -d-old plants grown at $20 / 15,30 / 25$, or $40 / 35^{\circ} \mathrm{C}$ day/night (D/N) and $16 / 8$ $\mathrm{h}$ photoperiod for 4 weeks. Chlorophyll content was measured with the leaf chlorophyll meter, at weekly intervals. Vertical lines through data points represent the SE; values smaller than symbols are not shown. Control values (SPAD units) are: 'Semillon' (30.46), 'Pinot Noir' (33.11), 'Chardonnay' (31.15), 'Cabernet Sauvignon' (32.63), and 'Cynthiana' (30). The control treatment was measured at $22 / 17 \pm 3^{\circ} \mathrm{C} \mathrm{D} / \mathrm{N}$ and $16 / 8 \mathrm{~h}$ photoperiod.

nificant differences between the cultivars grown at $40 / 35^{\circ} \mathrm{C}$. At 1 week of exposure, 'Chardonnay' had $123 \%$ chlorophyll content, which was the highest level, whereas 'Cynthiana' had the least (104\%). In contrast to V. vinifera cultivars, reduction in chlorophyll content was more pronounced in 'Cynthiana' after more than 2 weeks of exposure. After 4 weeks exposure to 40/35 ${ }^{\circ} \mathrm{C}$, 'Chardonnay', 'Pinot Noir', and 'Semillon' had 137\%, 131\%, and $124 \%$, respectively, chlorophyll content, compared with $64 \%$ for 'Cynthiana'.

LEAF CHLOROPHYLL FLUORESCENCE. Variable fluorescence of 'Semillon' declined by $23 \%$ after 2 weeks of exposure to 20/15 ${ }^{\circ} \mathrm{C}$, compared with week one. No changes were recorded in the other cultivars (Fig. 4). The Fv of 'Chardonnay', 'Cynthiana', and 'Semillon' grown at $30 / 25^{\circ} \mathrm{C}$ for 2 weeks decreased by $32 \%$, $25 \%$, and $21 \%$, respectively, whereas no change was observed in 'Pinot Noir' or 'Cabernet Sauvignon'. Four weeks of 30/25 ${ }^{\circ} \mathrm{C}$ significantly reduced $\mathrm{Fv}$ of all the cultivars, although the reduction was more severe in 'Cynthiana' (60\%), 'Chardonnay'

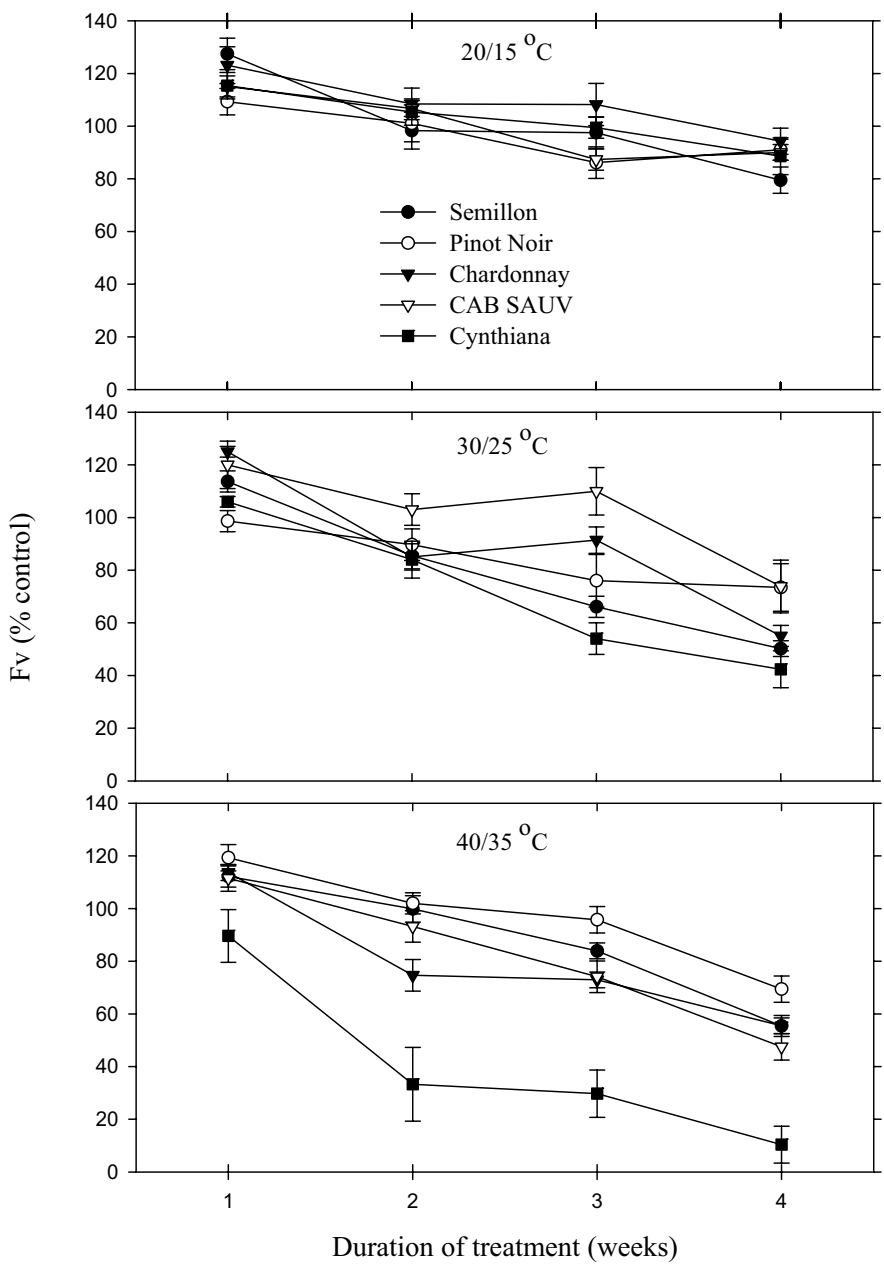

Fig. 4. Chlorophyll variable fluorescence (Fv) of attached leaves of Vitis vinifera 'Semillon', 'Pinot Noir', 'Chardonnay', 'Cabernet Sauvignon' (CAB SAUV), and V.aestivalis 'Cynthiana' after temperature treatments. Attached leaves were on 35-d-old plants grown at $20 / 15,30 / 25$, or $40 / 35^{\circ} \mathrm{C}$ day/night $(\mathrm{D} / \mathrm{N})$ and $16 / 8$ $\mathrm{h}$ photoperiod for 4 weeks. Chlorophyll fluorescence was measured as described in the Materials and Methods, at weekly intervals. Vertical lines through data points represent the SE; values smaller than symbols are not shown. Control values (relative units) are: 'Semillon' (1233), 'Pinot Noir'(1291), 'Chardonnay' (1277), 'Cabernet Sauvignon' (1226), and 'Cynthiana' (1302). The control treatment was measured at $22 / 17 \pm 3^{\circ} \mathrm{C} \mathrm{D} / \mathrm{N}$ and $16 / 8 \mathrm{~h}$ photoperiod.

(57\%), and 'Semillon' (56\%), compared with 'Pinot Noir' (25\%) or 'Cabernet Sauvignon' (38\%). Variable fluorescence decreased rapidly in all the cultivars after 2 weeks of $40 / 35^{\circ} \mathrm{C}$. Except for 'Chardonnay', Fv decline was less evident in V. vinifera cultivars than in 'Cynthiana'. Reduction of Fv after 2 weeks at $40 / 35^{\circ} \mathrm{C}$ was $63 \%$ in 'Cynthiana', relative to an average decline of $19 \%$ in the $V$. vinifera cultivars. Four weeks of exposure to $40 / 35^{\circ} \mathrm{C}, \mathrm{Fv}$ in 'Cynthiana' was reduced to $10 \%$ of the control, approximately an $89 \%$ reduction. 'Pinot Noir' had the highest Fv value (69\%) after 4 weeks of exposure to $40 / 35^{\circ} \mathrm{C}$, whereas 'Cynthiana' had the lowest value.

Differential responses of $\mathrm{Fv} / \mathrm{Fm}$ of all the cultivars to temperature treatments are shown in Fig. 5. After 2 weeks at the lowest temperature $\left(20 / 15^{\circ} \mathrm{C}\right), \mathrm{Fv} / \mathrm{Fm}$ ratio in 'Semillon' was decreased by $11 \%$, compared with that of week one, whereas no temperature response was evident in the other cultivars. As the time of exposure extended to 4 weeks, Fv/Fm of 'Semillon' was reduced by $16 \%$, whereas no significant changes were observed 

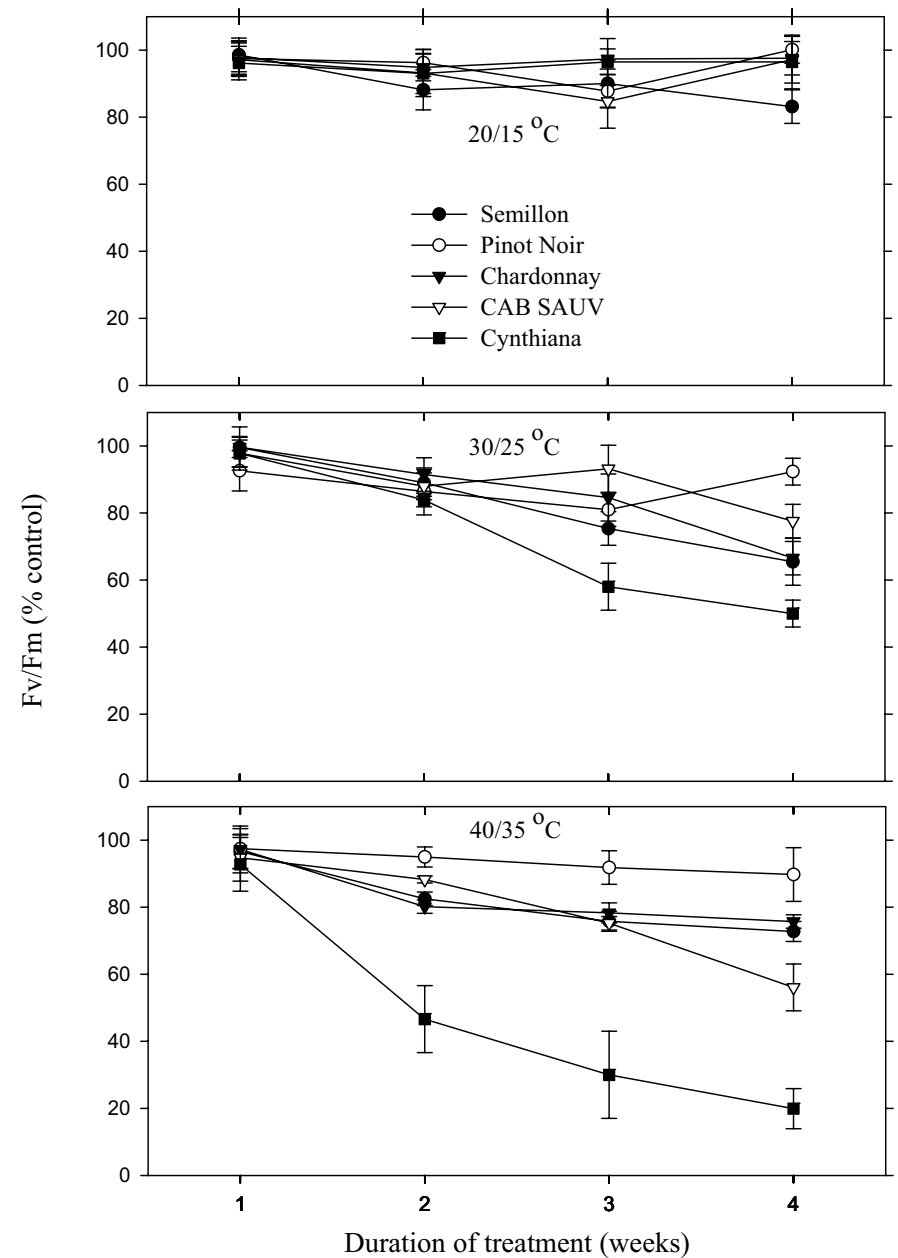

Fig. 5. Quantum efficiency of PSII (Fv/Fm) of attached leaves of Vitis vinifera 'Semillon', 'Pinot Noir', 'Chardonnay', 'Cabernet Sauvignon' (CAB SAUV), and V.aestivalis 'Cynthiana' after temperature treatments. Attached leaves were on 35-d-old plants grown at $20 / 15,30 / 25$, or $40 / 35^{\circ} \mathrm{C}$ day/night $(\mathrm{D} / \mathrm{N})$ and $16 / 8$ $\mathrm{h}$ photoperiod for 4 weeks. Fv/Fm was measured as described in the Materials and Methods, at weekly intervals. Vertical lines through data points represent the SE; values smaller than symbols are not shown. Control values (relative units) are: 'Semillon' (0.793), 'Pinot Noir' (0.797), 'Chardonnay' (0.801), 'Cabernet Sauvignon' (0.797), and 'Cynthiana' (0.811). The control treatment was measured at $22 / 17 \pm 3{ }^{\circ} \mathrm{C} \mathrm{D} / \mathrm{N}$ and $16 / 8 \mathrm{~h}$ photoperiod.

in the other cultivars. As time of exposure to $30 / 25^{\circ} \mathrm{C}$ increased, Fv/Fm ratios decreased in 'Cynthiana', 'Semillon', and 'Chardonnay'. There was $13 \%$ reduction in 'Pinot Noir' after 3 weeks of exposure; nevertheless, plants recovered thereafter and reached the same Fv/Fm ratio (93\%) as that of week one. After 4 weeks of exposure to $30 / 25^{\circ} \mathrm{C}$, 'Cynthiana' $\mathrm{Fv} / \mathrm{Fm}$ was reduced the most to $50 \%$, relative to the $V$. vinifera cultivars.

Two weeks at $40 / 35{ }^{\circ} \mathrm{C}, \mathrm{Fv} / \mathrm{Fm}$ ratios decreased in all the cultivars, except in 'Pinot Noir'. A sharp decline in 'Cynthiana' was observed by 2 weeks of exposure to $40 / 35^{\circ} \mathrm{C}$, which was reduced to $46 \%$ while other cultivars were above $80 \%$. After 4 weeks of exposure to $40 / 35^{\circ} \mathrm{C}, \mathrm{Fv} / \mathrm{Fm}$ ratio of 'Cynthiana' was reduced to $20 \%$ of the control, compared with $90 \%$ in 'Pinot Noir', 76\% in 'Chardonnay', 73\% in 'Semillon', and 57\% in 'Cabernet Sauvignon'.

EXTRACTED THYLAKOIDS FLUORESCENCE. Initial chlorophyll fluorescence (Fo) of extracted thylakoids from 'Cynthiana' and 'Pinot Noir' was not affected by $20^{\circ} \mathrm{C}$ (Fig. 6A). Significant dif-
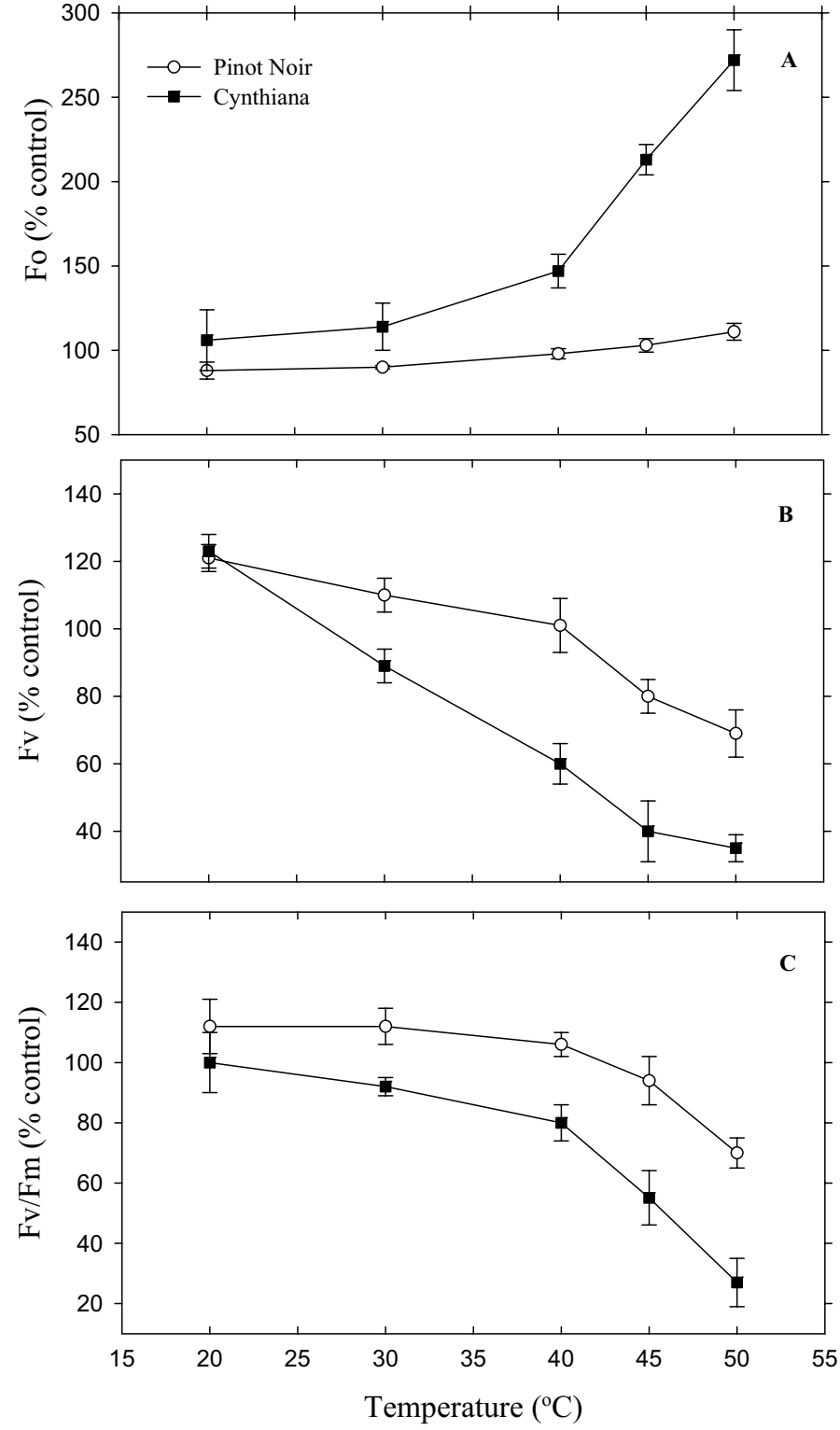

Fig. 6. Initial chlorophyll fluorescence $(\mathrm{Fo})(\mathbf{A})$, variable fluorescence $(\mathrm{Fv})(\mathbf{B})$, and quantum efficiency of PSII ( $\mathrm{Fv} / \mathrm{Fm})(\mathbf{C})$ of extracted thylakoids of Vitis vinifera 'Pinot Noir' and $V$. aestivalis 'Cynthiana' after temperature treatments of $20,30,40,45$, or $50^{\circ} \mathrm{C}$ for $2 \mathrm{~min}$. Thylakoids were extracted from leaves on 35 -d-old plants grown at $22 / 17 \pm 3^{\circ} \mathrm{C}$ day/night $(\mathrm{D} / \mathrm{N})$ and $16 / 8 \mathrm{~h}$ photoperiod for 4 weeks. Thylakoid extraction, treatments, and fluorescence measurements are as described in the Materials and Methods. Vertical lines through data points represent the SE; values smaller than symbols are not shown. Control values (relative units) for Fo, Fv, Fv/Fm, respectively, are: 'Pinot Noir' (49, 14, 0.2367) and 'Cynthiana' $(53,12,0.1943)$. The control treatment was measured at room temperature $\left(22-23{ }^{\circ} \mathrm{C}\right)$.

ferences between the two cultivars were evident as temperature increased by $10{ }^{\circ} \mathrm{C}$. The Fo increased in 'Cynthiana', compared with that of 'Pinot Noir', by $21 \%, 33 \%, 52 \%$, and $59 \%$ at 30,40 , 45 , and $50^{\circ} \mathrm{C}$, respectively. From 30 to $40^{\circ} \mathrm{C}$, Fo of 'Pinot Noir' thylakoids increased by $8 \%$, whereas $22 \%$ increase was recorded for 'Cynthiana'. The Fv (Fig. 6B) of the thylakoids was reduced more in 'Cynthiana' than in 'Pinot Noir.' Most of the decline in 'Cynthiana' was due to a decline in Fm (data not shown) and increase in Fo. Reduction in Fv was reflected in a steady decline in Fv/Fm (Fig. 6C). 


\section{Discussion}

Shiraishi et al. (1996) reported that optimal temperature for A is higher for $V$. vinifera cultivars than that of V.aestivalis cultivars, which was attributed to selection conducted for the cultivars under different temperature conditions in the cultivated areas (Chaves et al., 1987). In our study, optimal temperature for photosynthesis in 'Cynthiana' was $20 / 15^{\circ} \mathrm{C}$, whereas $30 / 25^{\circ} \mathrm{C}$ was optimum for 'Pinot Noir' and most of the other $V$. vinifera cultivars. At $40 / 35^{\circ} \mathrm{C}$, 'Cynthiana', followed by 'Semillon', were the most sensitive cultivars; 'Pinot Noir' was the most resistant; and the other $V$. vinifera cultivars were intermediate.

Net $\mathrm{CO}_{2}$ assimilation rate (Fig. 1), g (Fig. 2), chlorophyll content (Fig. 3), E (Table 1) rates, and intact leaf Fv/Fm (Fig. 5) were significantly lower in 'Cynthiana' at high temperature, relative to 'Pinot Noir' and most of the $V$. vinifera cultivars. 'Cynthiana' showed a linear decline in A rate as temperature increased to $40 / 35^{\circ} \mathrm{C}$. These findings support previous work that A declines in temperate fruit crops as temperature increases from 20 to 30 ${ }^{\circ} \mathrm{C}$ (Hancock et al., 1992).

In general, reduction in A of the $V$. vinifera cultivars at 40/35 ${ }^{\circ} \mathrm{C}$ was more closely related to changes in $\mathrm{Fv} / \mathrm{Fm}$ rather than $\mathrm{g}_{\mathrm{s}}$. 'Pinot Noir' had the highest A rate (Fig. 1) and Fv/Fm ratio and the lowest $g_{s}$ and $E$ rates, compared with the other $V$. vinifera cultivars, after 4 weeks of exposure to $40 / 35^{\circ} \mathrm{C}$. Nevertheless, reduction of $\mathrm{A}$ in 'Cynthiana' was related to reduction in both $\mathrm{g}_{\mathrm{s}}$ and $\mathrm{Fv} / \mathrm{Fm}$ ratio. Net $\mathrm{CO}_{2}$ assimilation rates were strongly related to $\mathrm{Fv} / \mathrm{Fm}$, with an average correlation coefficient $(r)$ of 0.92 (data not shown) across the cultivars, whereas A was less related to $g_{s}$ with an average correlation coefficient of 0.61 (data not shown). Photosynthetic rate of 'Cynthiana' was related to $\mathrm{g}_{\mathrm{s}}$ with correlation coefficient of 0.94 , whereas average correlation for $\mathrm{A}$ and $\mathrm{g}_{\mathrm{s}}$ for $V$. vinifera cultivars was 0.50 .

Results of studies on $g_{s}$ rates and their relationship to A during heat stress have been inconsistent. Some studies reported that $g_{s}$ rates increase with increasing temperature (Rogers et al., 1981), whereas others showed a decline (Candolfi-Vasconcelos and Koblet, 1991; Chaves et al., 1987; Ferrini et al., 1995). Decline of $\mathrm{g}_{\mathrm{s}}$ has been attributed to internal $\mathrm{CO}_{2}$ accumulation $\left(\mathrm{C}_{\mathrm{i}}\right)$, water stress, and hormonal changes that control stomatal activities (Gomez-Del-Campo et al., 2004). Reduction in Arates under drought stress, with no effect on $\mathrm{g}_{\mathrm{s}}$, has been attributed to nonstomatal factors such as carbohydrate accumulation, reduction in ribulose1,5-bisphosphate regeneration, or photoinhibition (Medranoet al., 2003). In this study, drought stress was not a factor and measurement of hormonal changes during heat stress was not conducted; thus, photoinhibition, or a decrease in quantum efficiency of PSII, might be one of the main factors for A reduction.

A positive relationship between $\mathrm{g}_{\mathrm{s}}$ and $\mathrm{E}$ rates is observed in this study. The lowest $g_{s}$ values of 'Pinot Noir' and 'Cynthiana' after 4 weeks of exposure to high temperature coincided with the lowest $\mathrm{E}$ rates, which agrees with earlier report that $g_{s}$ is positively related to E rate (Stafne et al., 2001). Chlorophyll content (Fig. 3) of 'Cynthiana' declined as temperature increased to $40 / 35^{\circ} \mathrm{C}$, whereas no changes were recorded in most of the $V$. vinifera cultivars. Leaves of 'Pinot Noir' and 'Chardonnay' had the highest A rates and chlorophyll content at $40 / 35^{\circ} \mathrm{C}$, whereas 'Cynthiana' leaves had the lowest values. These findings indicate that a positive relationship between $\mathrm{A}$ and chlorophyll content existed, which agrees with earlier reports that an increase in A is related to an increase in chlorophyll content at $35^{\circ} \mathrm{C}$ (Ferrini et al., 1995). Higher chlorophyll content of 'Pinot Noir' relative to 'Cynthiana' indicates that the latter was not utilizing the light harvesting pigments as efficiently as 'Pinot Noir' (Candolfi-Vasconcelos and Koblet, 1991).

Environmental stresses increase Fo and decrease Fv/Fm, which indicates dissociation of the light harvesting pigments from the PSII core, resulting in reduction in photochemical efficiency of PSII (Kitao et al., 2000; Wise et al., 2004). Thermostability of extracted thylakoid behaved similarly to whole-plant responses to high temperature. After 2 min exposure to temperatures higher than $20^{\circ} \mathrm{C}$, extracted thylakoids from 'Cynthiana' showed an increase in Fo (Fig. 6A) and decrease in Fv (Fig. 6B) and Fv/Fm (Fig. 6C). Reduction in Fv was more severe in 'Cynthiana' than in 'Pinot Noir'. Most of the decline of Fv in 'Cynthiana' was due to a decline in Fm (data not shown) and an increase in Fo. The lowest $\mathrm{Fv} / \mathrm{Fm}$ values indicate that electron transfer from PSII in 'Cynthiana' subjected to temperature higher than 20 ${ }^{\circ} \mathrm{C}$ is less efficient than that of 'Pinot Noir' (Kitao et al., 2000; Sharkey, 2000). A sharp decline in leaf $\mathrm{Fv} / \mathrm{Fm}$ at $40 / 35^{\circ} \mathrm{C}$ was a good indicator that irreversible damage occurred to PSII of 'Cynthiana'. The high resistance of intact leaves of 'Pinot Noir' to $40 / 35{ }^{\circ} \mathrm{C}$ could be attributed to thermostability of the thylakoid membranes subjected to temperatures ranging between 20 to $50{ }^{\circ} \mathrm{C}$. Results of this study agree with an earlier report that thermostability of resistant thylakoids is essential for the stability of photosynthesis (Al-Khatib and Paulsen, 1999; DeEll and Toivonen, 2000). Responses of chlorophyll fluorescence of intact leaves and extracted thylakoids to high temperatures indicate that 'Pinot Noir' possesses higher potential photosynthetic activity at high temperatures than 'Cynthiana'.

This study was conducted to determine how two Vitis species responded to three temperatures under controlled environmental conditions. Differences among grapevine cultivars in response to heat stress have been identified. 'Pinot Noir' was the most resistant cultivar, having minimal decline in A, chlorophyll content, and less decline in Fv/Fm, compared with 'Cynthiana', which proved to be the cultivar most sensitive to high temperature. Optimal temperatures for photosynthesis were $20 / 15^{\circ} \mathrm{C}$ and $30 / 25^{\circ} \mathrm{C}$ for 'Cynthiana' and most of the V. vinifera cultivars, respectively. Photosynthesis in 'Cynthiana' was affected both by stomatal activities and by decline in the $\mathrm{Fv} / \mathrm{Fm}$ ratio, whereas A was less related to $\mathrm{g}_{\mathrm{s}}$, but more to $\mathrm{Fv} / \mathrm{Fm}$ ratio in $V$. vinifera cultivars.

\section{Literature Cited}

Al-Khatib, K. and G. Paulsen. 1990. Photosynthesis and productivity during high-temperatures stress of wheat genotypes from major world regions. Crop Sci. 30:1127-1132.

Al-Khatib, K. and G. Paulsen. 1999. High temperature effects on photosynthetic processes in temperate and tropical cereals. Crop Sci. 39:119-125.

Armond, P.A., O. Björkman, and L.A. Staehelin. 1980. Dissociation of supramolecular complexes in chloroplast membranes. A manifestation of heat damage to photosynthetic apparatus. Biochimica Biophysica Acta Biomembranes 601:433-442.

Berry, J.A. and O. Björkman. 1980. Photosynthetic response and adaptation to temperature in higher plants. Ann. Rev. Plant Physiol. 31:491-543.

Blanke, M.M. 1990. Carbon economy of grape inflorescence. V: Energy requirement of flower bud of grape. Viticult. Enol. Sci. 45:33-40.

Candolfi-Vasconcelos, M.C. and W. Koblet. 1991. Influence of partial defoliation on gas exchange parameters and chlorophyll content of fieldgrown grapevines-Mechanisms and limitations of the compensation capacity. Vitis 30:129-141.

Chaves, M.M., P.C. Harley, J.D. Tenhunen, and O.L. Lange. 1987. Gas 
exchange studies in two Portuguese grapevine cultivars. Physiol. Plant. 70:639-647.

DeEll, J. and P.M.A. Toivonen. 2000. Chlorophyll fluorescence as a nondestructive indicator of broccoli quality during storage in modified-atmosphere packaging. HortScience 35:256-259.

Dubey, R.S. 1997. Photosynthesis in plants under stressful conditions, p. 859-875. In: M. Pessarakli (ed.). Handbook of photosynthesis. CRC Press, Boca Raton, Fla.

Ewart,A. and W.M. Kliewer. 1977. Effect of controlled day and night temperatures and nitrogen on fruit set, ovule fertility and fruit composition on several wine grape cultivars. Amer. J. Enol. Viticult. 28:88-95.

Falk, S., D.P. Maxwell, D.E. Laudenbach, and N.P.A. Huner. 1996. Photosynthetic adjustment to temperature, p. 367-385. In: N.R. Baker (ed.). Advances in photosynthesis: Photosynthesis and environment. Vol. 5. Kluwer Academic Publishers, Dordrecht, The Netherlands.

Ferrini, F., G.B. Mattii, and F.P. Nicese. 1995. Effect of temperature on key physiological responses of grapevine leaf. Amer. J. Enol. Viticult. 46:375-379.

Gamon, J.A. and R.W. Pearcy. 1990. Photoinhibition on Vitis californica: Interactive effect of sunlight, temperature and water status. Plant Physiol. 92:487-494.

Gomez-Del-Campo, M., P. Baeza, C. Ruiz, and J.R. Lissarrague. 2004. Water-stress induced physiological changes in leaves of four containergrown grapevine cultivars (Vitis vinifera L.). Vitis 43:99-105.

Gounaris, K., A.P.R. Brain, P.J. Quinn, and W.P. Williams. 1983. Structural and functional changes associated with heat-induced phase separations of non-bilayer lipids in chloroplast thylakoid membranes. FEBS Lett. 153:47-53.

Haldimann, P. and U. Feller. 2005. Growth at moderately elevated temperature alters the physiological response of photosynthetic apparatus to heat stress in pea (Pisum sativum L.) leaves. Plant Cell Environ. 28:302-317.

Hancock, J.F., K. Haghighi, S.L. Kerbs, J.A. Flore, and A.D. Draper. 1992. Photosynthetic heat stability in highbush blueberry and possibility of genetic improvement. HortScience 27:1111-1112.

Kim, K. and A.R. Portis, Jr. 2005. Temperature dependence of photosynthesis in Arabidopsis plants with modifications in Rubisco activase and membrane fluidity. Plant Cell Physiol. 46:522-530.

Kitao, M., T.T. Lei, T. Koike, H. Tobita, and Y. Maruyama. 2000. Susceptibility to photoinhibition of three deciduous broadleaf tree species with different successional traits raised under various light regimes. Plant Cell Environ. 23:81-89.

Kliewer, W.M. 1968. Effect of temperature on composition of grapes grown under field and controlled conditions. Proc. Amer. Soc. Hort. Sci. 93:797-806.

Kliewer, W.M. 1970. Effect of day temperature and light intensity on coloration of Vitis vinifera L. grapes. J. Amer. Soc. Hort. Sci. 95:693-697.

Kliewer, W.M. 1971. Effect of day temperature and light intensity on concentrations of malic and tartaric acids in Vitis vinifera L. grapes. J. Amer. Soc. Hort. Sci. 96:372-377.

Kobza, J. And G.E. Edwards. 1987. Influences of leaf temperature on photosynthetic carbon metabolism in wheat. Plant Physiol. 83:69-74.

Li, Z., K. Nada, and S. Tachibana. 2003. High-temperature induced alteration of $\mathrm{ABA}$ and polyamine contents in leaves and its implication in thermal acclimation of photosyntehsis in cucumber (Cucumis sativus L.). J. Jpn. Soc. Hort. Sci. 72:393-401.
Medrano, H., J.M. Escalona, J. Cifre, J. Bota, and J. Flexas. 2003. A tenyear study on the physiology of two Spanish grapevine cultivars under field conditions: Effect of water availability from leaf photosynthesis to grape yield and quality. Functional Plant Biol. 30:607-619.

Moffatt, J.M., R.G. Sears, and G. Paulsen. 1990. Wheat high temperature tolerance during reproductive growth. I. Evaluation by chlorophyll fluorescence. Crop Sci. 30:881-885.

Mullins, M.G., A. Bouquet, and L.E. Williams. 1992. Biology of the grapevine. Cambridge Univ. Press, Cambridge, England.

Olson, B.L.S., K. Al-Khatib, P. Stahlman, and P.J. Isakson. 2000. Efficacy and metabolism of MON 37500 in Tititicum aestivum and weedy grass species as affected by temperature and soil moisture. Weed Sci. 48:541-548.

Ramsey, F.L. and D.W. Schafer. 1997. The statistical sleuth, p. 91-97. A course in methods of data analysis. Duxbury Press, Belmont, Calif.

Rogers, C., P.J.H. Sharpe, R.D. Powell, and R.D. Spencer. 1981. High temperature disruption of guard cells of Vicia faba. Plant Physiol. 67:193-196.

Salvucci, M.E. and S.J. Crafts-Brandner. 2004. Inhibition of photosynthesis by heat stress: The activation state of Rubisco as a limiting factor in photosynthesis. Physiol. Plant. 120:179-186.

Santarius, K.A. 1975. Sites of heat sensitivity in chloroplasts and differential inactivation of cyclic and noncyclic photophosphorylation by heating. J. Thermal Biol. 1:101-107.

Schrader, S.M., R.R. Wise, W.F. Wacholtz, D.R. Ort, and T.D. Sharkey. 2004. Thylakoid membrane responses to moderately high leaf temperature in pima cotton. Plant Cell Environ. 27:725-735.

Sepulveda, G., W.M. Kliewer, and K. Ryugo. 1986. Effect of high temperature on grapevines (Vitis vinifera L.). I. Translocation of 14-C photosynthates. Amer. J. Enol. Viticult. 37:13-19.

Sharkey, T.D. 2000. Some like it hot. Science 287:435-436.

Sharkey, T.D. 2005. Effects of moderate heat stress on photosynthesis: Importance of thylakoid reactions, rubisco deactivation, reactive oxygen species, and thermotolerance provided by isoprene. Plant Cell Environ. 28:269-277.

Shiraishi, S.I., T.C. Hsiung, M. Shiraishi, and M. Kitazaki. 1996. Effects of temperature on the photosynthesis rate of grape cultivars. Sci. Bul. Faculty Agr. Kyushu Univ. 51:9-16.

Song, G. and K.C. Ko. 1999. Effect of climatic conditions during blooming on the berry setting of 'Kyoho' (Vitis labruscana B.) grapevine. J. Korean Soc. Hort. Sci. 40:75-78.

Stafne,E.T., J.R. Clark, and C.R. Rom. 2001. Leaf gas exchange response of 'Arapaho' blackberry and six red raspberry cultivars to moderate and high temperatures. HortScience 36:880-883.

Tardy, F. and M. Havaux. 1997. Thylakoid membrane fluidity and thermostability during the operation of xanthophylls cycle in higherplant chloroplast. Biochimica Biophysica Acta Biomembranes 1330:179-193.

Williams, L.E., N.K. Dokoozlian, and R. Wample. 1994. Grape, p. 358-367. In: B. Schaffer and P.C. Anderson (eds.). Handbook of environmental physiology of fruit crops. vol. I. Temperate crops, CRC Press, Boca Raton, Fla.

Wise, R.R., A.J. Olson, S.M. Schrader, and T.D. Sharkey. 2004. Electron transport is the functional limitation of photosynthesis in fieldgrown pima cotton plants at high temperature. Plant Cell Environ. 27:717-724. 